\title{
Risk Factors for Obesity and Time Frame of Weight Gain in Non-Irradiated Survivors of Pediatric Acute Lymphoblastic Leukemia
}

\author{
Maheen Hassan ${ }^{1}$, Carol H. Lin ${ }^{2}$, Lilibeth Torno ${ }^{2 *}$ \\ ${ }^{1}$ Department of Pediatrics, Children's Hospital \& Research Center Oakland, Oakland, USA; ${ }^{2}$ The Hyundai Cancer Institute, Chil- \\ dren's Hospital of Orange County, Orange, USA. \\ Email: *1torno@choc.org
}

Received November $11^{\text {th }}, 2012$; revised December $13^{\text {th }}, 2012$; accepted December $22^{\text {nd }}, 2012$

\begin{abstract}
Background: Obesity has been described among survivors of pediatric Acute Lymphoblastic Leukemia (ALL), especially those who have received cranial radiation. This study aims to evaluate the prevalence of overweight or obesity in pediatric ALL survivors who were not exposed to radiation, identify the time frame in which the rate of obesity rise is the greatest, and identify contributing clinical and treatment variables. Methods: In this retrospective, single institution study, the charts of 132 ALL survivors were reviewed. Odds Ratios (OR) and 95\% Confidence Intervals (CI) were calculated for being overweight or obese at their 2-year follow-up for the following clinical variables: ethnicity, age at diagnosis, and weight at diagnosis. Changes in BMI percentiles between 4 different time points were assessed using t-test comparison and p values. Results: Survivors of ALL were more likely to be overweight or obese than the general population at the 2- and 5-year follow-up. White and Hispanic ethnicity and being overweight or obese at diagnosis were also risk factors for being overweight or obese 2 years after the end of treatment. When looking at the time frame of weight gain, survivors had a significant increase in BMI percentile between diagnosis and end of therapy, and between diagnosis and 2-year follow-up, but did not have a significant increase between end of therapy and 2-year follow-up. Conclusion: Patients with ALL have an increased risk of being obese at follow-up. They show early weight gain, between diagnosis and end of treatment, and remain overweight/obese long term. Ethnicity and BMI weight category at diagnosis were significant influences. A strategic plan to prevent this weight gain should be implemented early during therapy.
\end{abstract}

Keywords: Acute Lymphoblastic Leukemia; Obesity; Body Mass Index

\section{Introduction}

During the past 20 years, there has been a dramatic increase in obesity rates in the United States, with the prevalence among children almost tripled since 1980 [1]. Obesity is a well recognized late effect in survivors of childhood acute lymphoblastic leukemia (ALL) and has been reported in some subgroups of pediatric patients with brain tumors [2,3]. Treatment of ALL is based on Children's Oncology Group (COG) protocols, which are stratified according to risk of relapse based on several factors such as age and white blood cell count at diagnosis, response to initial treatment, minimal residual disease testing, cytogenetics, and extramedullary involvement. Standard risk patients start with induction phase consisting of three drugs: vincristine, steroids, and asparaginase. High risk patients are treated initially with four drugs, the fourth being doxorubicin. The number of survivors of

${ }^{*}$ Corresponding author. childhood cancer has been steadily increasing with progressive improvements in therapy, with children diagnosed with ALL having a 5-year survivor rate of $82.3 \%$, according to the Surveillance Epidemiology and End Result (SEER) data [4]. This expanding population of ALL survivors mandates better characterization of the long term complications of treatment to improve our understanding of their future health risks as over $70 \%$ of survivors face at least one or more adverse effects of treatment later in life [5]. There are studies that have characterized the Body Mass Index (BMI) distribution in survivors of ALL; however, the majority of these are muddled with confounding factors. The percentage of children who receive cranial radiation as a component of treatment has been reduced [6]. Though the underlying pathophysiology of radiation exposure to the hypothalamic-pituitary-adrenal (HPA) axis remains unclear, it is known that the hypothalamic centers are responsible for regulating satiety, hunger, and energy balance. Disrup- 
tion of insulin and leptin signaling may contribute to hypothalamic obesity. Radiation to the suprachiasmatic hypothalamic nucleus may also contribute to obesity [7]. The sympathetic and parasympathetic nerves that innervate adipose tissue and regulate lipolysis and lipogenesis, respectively, originate at the suprachiasmatic hypothalamic nucleus. Damage to this area may predispose to alterations in metabolism. Although radiation can contribute to several pituitary hormone deficiencies, there is evidence that growth hormone is most sensitive to these effects [6]. Growth hormone deficiency can cause decreased lean body mass, increased percentage of body fat, abnormal lipoprotein metabolism, increased peripheral insulin resistance, and impaired glucose tolerance. Various studies, including The Childhood Cancer Survivor Study (CCSS), have demonstrated a dose-dependent effect of cranial radiation, with an increased risk of obesity in both males and females if treated with radiation doses greater than $20 \mathrm{~Gy}$ to $30 \mathrm{~Gy}$ [8-11]. Others have shown that even low dose radiation, 18 Gy to $20 \mathrm{~Gy}$, can predispose females to obesity $[12,13]$.

In this study, we looked at survivors of ALL who were not exposed to radiation and determined 1) if obesity is more prevalent after treatment; 2) identified the time frame in which the rate of obesity rise is the greatest; and 3 ) identified contributing treatment variables.

\section{Methods}

\subsection{Data Collection}

After obtaining approval from our Institutional Review Board (IRB) we retrospectively reviewed the medical records of 283 patients with pediatric ALL seen in the CHOC Children's Hospital after Cancer Treatment Survivorship (ACTS) program. Of these 283, 132 patients' charts were included in the analysis based on the criteria further described below. ACTS is a multidisciplinary clinic that follows survivors until 21 years of age. Most patients are seen on a yearly basis, enabling data to be collected frequently on active patients. Abstracted data included type of cancer, age at cancer diagnosis, therapy received (location and quantity of radiation, surgery, bone marrow transplant (BMT), chemotherapy), ethnicity, and weight and height at 4 different time points (time of diagnosis, end of therapy, 2 years after end of therapy, and 5 years after end of therapy). Exclusion criteria included patients with relapse, death, irradiation (cranial, testicular, or total body), BMT, or other co-existing conditions that may affect long-term growth (Down's syndrome, hypothyroidism, growth hormone deficiency).

\subsection{Outcome Measures}

BMI was calculated by dividing weight in kilograms by height in meters squared. Patients were classified as underweight, normal weight, overweight, or obese at the 4 different time points measured. For patients between 2 and 20 years old, BMI was converted to a percentile corrected for age and sex based on the Centers for Disease Control (CDC) 2000 growth charts [14]. Since BMI varies considerably with age in children, BMI percentiles are the most commonly used indicator to assess the size and growth patterns of individual children in the United States $[15,16]$. Patients were divided by BMI percentile for age and sex accordingly: 1) $<5$ th percentile classified as underweight; 2) 5th to 84.9th percentile classified as normal weight; 3) 85th to 94.9 th percentile classified as overweight; and 4) $>95$ th percentile classified as obese. For patients older than 20, the widely accepted BMI values were used to classify weight: $<18.5 \mathrm{~kg} / \mathrm{m}^{2}$ for underweight, 18.5 to $24.9 \mathrm{~kg} / \mathrm{m}^{2}$ for normal weight, 25.0 to $29.9 \mathrm{~kg} / \mathrm{m}^{2}$ for overweight, and $\geq 30 \mathrm{~kg} / \mathrm{m}^{2}$ for obese.

\subsection{Data Analysis}

Descriptive statistics were used to summarize demographic and clinical variables. The frequency and percentages of each variable were calculated for the study population. The relative odds of having BMI $\geq 85$ th percentile among ALL cancer survivors when compared to population norms from the 2007-2008 National Health and Nutrition Examination Survey (NHANES) were calculated separately for all survivors as well as by ethnicity. The odds ratio of having BMI $\geq 85$ th percentile was also calculated for ALL survivors by age at diagnosis. Those under 4 years of age and those between ages 4 and 10 at diagnosis were individually compared to the reference group (survivors diagnosed at $\geq 10$ years of age). Lastly, the odds ratio of having BMI $\geq 85$ th percentile was calculated for ALL survivors by weight category at diagnosis. Those who were underweight or overweight/obese at diagnosis were compared to the reference group (normal weight at diagnosis). Change in BMI percentile over time was assessed by evaluating differences in the mean BMI percentile between 4 different time points: time of diagnosis, end of treatment, 2 years after end of treatment, and 5 years after end of treatment. Results are presented as means and 95\% confidence intervals, with $\mathrm{p}$ values from t-test comparisons.

\section{Results}

\subsection{Distribution of Weight Groups}

Among the 283 ALL survivors, 132 had documentation stating no known prior syndrome which can potentially affect weight, no radiation therapy, and no BMT. These 132 patients also had data at our three desired time points: 
time of diagnosis, end of therapy, and 2 years after end of therapy. Of these 132 patients, 93 had additional data at the fourth desired point, i.e., at 5 years after end of therapy. 151 ALL survivors were excluded from the study: 104 did not have data at our three desired time points, 15 had relapse, 18 had radiation only, 13 received BMT and radiation, and one patient had multiple trisomies $(3,10$, and 17).

Table 1 shows the patient demographics for ALL survivors who had follow-up 2 years after therapy. There were 65 females (49.2\%) and 67 males (50.7\%). Patients were diagnosed with ALL between August 1991 and May 2007. The median age at the time of cancer diagnosis was 4.5 years (range, 20 months to 19 years). The total number of patients under the age of 10 at diagnosis was $113(85.6 \%)$.

Tables 2(a) and (b) show the BMI percentile distributions at 2-year follow-up by ethnicity, age at diagnosis, weight category at diagnosis, and steroid treatment received, for females and males, respectively. Of the 132 ALL survivors in the cohort who were followed through two years of follow-up, $1(0.8 \%)$ was underweight, 62 $(47.0 \%)$ were normal weight, $69(52.3 \%)$ were overweight or obese. Of the 93 ALL survivors who were followed 5 years after the end of treatment, $0(0.0 \%)$ were underweight, $47(50.5 \%)$ were normal weight, and 46 $(49.5 \%)$ were overweight or obese (data not shown).

\subsection{Predictive Factors for Overweight/Obesity}

Table 3 shows the Odds Ratios (ORs) and 95\% confidence intervals $(\mathrm{CI})$ of having a $\mathrm{BMI} \geq 85$ th percentile at the 2-year follow-up. Female and male ALL survivors were significantly more likely to be overweight or obese than the general population [17] $(\mathrm{OR}=2.1 ; 95 \% \mathrm{CI}, 1.3$ 3.4 for females and $\mathrm{OR}=2.6 ; 95 \% \mathrm{CI}, 1.6-4.3$ for males). At the 5 year follow-up (data not shown), the same trend was seen $(\mathrm{OR}=1.9 ; 95 \% \mathrm{CI}, 1.0-3.4$ for females and $\mathrm{OR}=2.3 ; 95 \% \mathrm{CI}, 1.3-4.0$ for males).

When ethnicity was compared, white males were more likely than the general population to be overweight or obese 2 years after the end of treatment $(\mathrm{OR}=2.3 ; 95 \%$

Table 1. Patient demographics of ALL patients at diagnosis.

\begin{tabular}{|c|c|c|c|}
\hline & TOTAL 132 & FEMALES 65 & MALES 67 \\
\hline \multicolumn{4}{|l|}{ Ethnicity } \\
\hline White & 52 & 25 & 27 \\
\hline Hispanic & 71 & 33 & 38 \\
\hline Asian & 7 & 6 & 1 \\
\hline Black & 0 & 0 & 0 \\
\hline Other & 2 & 1 & 1 \\
\hline \multicolumn{4}{|l|}{ Age at diagnosis } \\
\hline $0-4$ & 77 & 38 & 39 \\
\hline $5-9$ & 36 & 21 & 15 \\
\hline$>=10$ & 19 & 6 & 13 \\
\hline \multicolumn{4}{|c|}{ BMI weight category at diagnosis } \\
\hline Underweight & 9 & 3 & 6 \\
\hline Normal & 76 & 39 & 37 \\
\hline Overweight/Obese & 47 & 23 & 24 \\
\hline \multicolumn{4}{|c|}{ Steroids received during treatment } \\
\hline Dex only & 75 & 44 & 31 \\
\hline Pred only & 4 & 1 & 3 \\
\hline Dex + Pred & 52 & 19 & 33 \\
\hline No documentation & 1 & 1 & 0 \\
\hline
\end{tabular}

Abbreviations: BMI, body mass index; Dex, dexamethasone; Pred, prednisone. 
Table 2. (a) Percentage of female ALL survivors in different BMI categories at 2-year follow-up by ethnicity, age at diagnosis, weight category at diagnosis, and steroid treatment; (b) Percentage of male ALL survivors in different BMI categories at 2-year follow-up by ethnicity, age at diagnosis, weight category at diagnosis, and steroid treatment.

(a)

\begin{tabular}{|c|c|c|c|c|}
\hline Characteristics & Total & $\begin{array}{l}\text { BMI }<5 \text { th percentile } \\
\text { Underweight No. }(\%)\end{array}$ & $\begin{array}{l}\text { BMI 5th - 85th percentile } \\
\text { Normal No. }(\%)\end{array}$ & $\begin{array}{c}\text { BMI } \geq 85 \text { th percentile } \\
\text { Overweight/Obese No. (\%) }\end{array}$ \\
\hline GENERAL POPULATION & & $(3.3)$ & $(63.8)$ & $(31.9)$ \\
\hline FEMALES & 65 & $1(1.5)$ & $32(49.2)$ & $32(49.2)$ \\
\hline \multicolumn{5}{|l|}{ Ethnicity } \\
\hline White & 25 & $0(0.0)$ & $16(64.0)$ & $8(32.0)$ \\
\hline Hispanic & 33 & $0(0.0)$ & $12(36.4)$ & $21(63.6)$ \\
\hline Asian & 6 & $1(16.7)$ & $3(50.0)$ & $2(33.3)$ \\
\hline Black & 0 & $0(0.0)$ & $0(0.0)$ & $0(0.0)$ \\
\hline Other & 1 & $0(0.0)$ & $1(100.0)$ & $0(0.0)$ \\
\hline \multicolumn{5}{|l|}{ Age at diagnosis } \\
\hline $0-4$ & 38 & $1(2.6)$ & $19(50.0)$ & $18(47.4)$ \\
\hline $5-9$ & 21 & $0(0.0)$ & $11(52.4)$ & $10(47.6)$ \\
\hline$>=10$ & 6 & $0(0.0)$ & $2(33.3)$ & $4(66.7)$ \\
\hline \multicolumn{5}{|c|}{ BMI weight category at diagnosis } \\
\hline Underweight & 3 & $0(0.0)$ & $2(66.7)$ & $1(33.3)$ \\
\hline Normal & 39 & $1(2.6)$ & $23(59.0)$ & $15(38.5)$ \\
\hline Overweight/Obese & 23 & $0(0.0)$ & $7(30.4)$ & $16(69.6)$ \\
\hline \multicolumn{5}{|l|}{ Steroids } \\
\hline Dex only & 44 & $0(0.0)$ & $23(52.3)$ & $21(47.7)$ \\
\hline Pred only & 1 & $0(0.0)$ & $1(100.0)$ & $0(0.0)$ \\
\hline Dex + Pred & 19 & $1(5.3)$ & $8(42.1)$ & $9(47.4)$ \\
\hline No Documentation & 1 & $0(0.0)$ & $0(0.0)$ & $1(100.0)$ \\
\hline
\end{tabular}

(b)

\begin{tabular}{|c|c|c|c|c|}
\hline Characteristics & Total & $\begin{array}{l}\text { BMI }<5 \text { th percentile } \\
\text { Underweight No. }(\%)\end{array}$ & $\begin{array}{l}\text { BMI 5th - 85th percentile } \\
\text { Normal No. }(\%)\end{array}$ & $\begin{array}{c}\text { BMI } \geq 85 \text { th percentile } \\
\text { Overweight/Obese No. (\%) }\end{array}$ \\
\hline GENERAL POPULATION & & $(3.3)$ & $(63.8)$ & $(31.9)$ \\
\hline MALES & 67 & $0(0.0)$ & $30(44.8)$ & $37(55.2)$ \\
\hline \multicolumn{5}{|l|}{ Ethnicity } \\
\hline White & 27 & $0(0.0)$ & $13(48.1)$ & $14(51.9)$ \\
\hline Hispanic & 38 & $0(0.0)$ & $16(42.1)$ & $22(57.9)$ \\
\hline Asian & 1 & $0(0.0)$ & $0(0.0)$ & $1(100.0)$ \\
\hline Black & 0 & $0(0.0)$ & $0(0.0)$ & $0(0.0)$ \\
\hline Other & 1 & $0(0.0)$ & $1(100.0)$ & $0(0.0)$ \\
\hline \multicolumn{5}{|l|}{ Age at diagnosis } \\
\hline $0-4$ & 39 & $0(0.0)$ & $14(35.9)$ & $25(64.1)$ \\
\hline $5-9$ & 15 & $0(0.0)$ & $10(66.7)$ & $5(33.3)$ \\
\hline$>=10$ & 13 & $0(0.0)$ & $6(46.2)$ & $7(53.8)$ \\
\hline \multicolumn{5}{|c|}{ BMI weight category at diagnosis } \\
\hline Underweight & 6 & $0(0.0)$ & $2(33.3)$ & $4(66.7)$ \\
\hline Normal & 37 & $0(0.0)$ & $22(59.5)$ & $15(40.5)$ \\
\hline Overweight/Obese & 24 & $0(0.0)$ & $6(25.0)$ & $18(75.0)$ \\
\hline \multicolumn{5}{|l|}{ Steroids } \\
\hline Dex only & 31 & $0(0.0)$ & $13(41.9)$ & $18(58.1)$ \\
\hline Pred only & 3 & $0(0.0)$ & $3(100.0)$ & $0(0.0)$ \\
\hline Dex + Pred & 33 & $0(0.0)$ & $14(42.4)$ & $19(57.6)$ \\
\hline No documentation & 0 & $0(0.0)$ & $0(0.0)$ & $0(0.0)$ \\
\hline
\end{tabular}

(a) Abbreviations: BMI, body mass index; Pop, population; Dex, dexamethasone; Pred, prednisone; (b) Abbreviations: BMI, body mass index; Dex, dexamethasone; Pred, prednisone. 
Table 3. Relative odds of being overweight or obese at 2-year follow-up.

\begin{tabular}{|c|c|c|c|c|}
\hline & \multicolumn{2}{|c|}{ FEMALES } & \multicolumn{2}{|c|}{ MALES } \\
\hline & ODDS & CONFIDENCE INTERVAL & ODDS & CONFIDENCE INTERVAL \\
\hline \multicolumn{5}{|l|}{ Diagnosis } \\
\hline ALL & 2.1 & 1.3 to 3.4 & 2.6 & 1.6 to 4.3 \\
\hline White & 1.0 & 0.4 to 2.3 & 2.3 & 1.1 to 4.9 \\
\hline Hispanic & 3.7 & 1.8 to 7.6 & 2.9 & 1.5 to 5.6 \\
\hline Asian & 1.1 & 0.2 to 5.8 & 0.0 & - \\
\hline Black & 0.0 & - & 0.0 & - \\
\hline Other & 0.0 & - & 0.0 & - \\
\hline \multicolumn{5}{|l|}{ Age at diagnosis } \\
\hline $0-4$ & 0.4 & 0.1 to 2.3 & 2.0 & 0.7 to 6.0 \\
\hline $5-9$ & 0.3 & 0.0 to 1.9 & 1.3 & 0.4 to 4.6 \\
\hline$>=10^{*}$ & 1.0 & Reference & 1.0 & Reference \\
\hline \multicolumn{5}{|c|}{ BMI wt category at diagnosis } \\
\hline Underweight & 0.8 & 0.1 to 9.6 & 2.9 & 0.5 to 18.1 \\
\hline Normal $^{*}$ & 1.0 & Reference & 1.0 & Reference \\
\hline Overweight/Obese & 3.7 & 1.2 to 11.0 & 4.4 & 1.4 to 13.7 \\
\hline
\end{tabular}

Abbreviations: ALL, acute lymphoblastic leukemia; BMI, body mass index; wt, weight. *Reference Group.

CI, 1.1 - 4.9). Of the 27 white males, $51.9 \%$ were in this weight category. Both Hispanic females and males were also more likely to be overweight or obese than the general population $(\mathrm{OR}=3.7 ; 95 \% \mathrm{CI}, 1.8-7.6$ for females and $\mathrm{OR}=2.9 ; 95 \% \mathrm{CI}, 1.5-5.6$ for males). Of the 33 Hispanic females and 38 Hispanic males, $63.6 \%$ and $57.9 \%$ were in this weight category, respectively. A similar trend was seen at the 5 year follow-up, though the only significant finding was for white and Hispanic males (OR 2.3; 95\% CI, $1.3-4.0$ for whites and OR = $2.9 ; 95 \%$ CI, 1.5 - 5.8 for Hispanics). Both Hispanics and whites consistently showed a greater propensity for overweight/obesity over other ethnic groups (Asian, Black, others), with Hispanics having the highest odds ratio amongst all ethnicities for being overweight or obese.

Age at diagnosis did not increase the risk of being overweight or obese. Weight category at diagnosis was significant for predicting overweight/obesity at 2 years post-treatment. Both males and females whose BMI was $\geq 85$ th percentile at diagnosis showed increase likelihood of being overweight/obese at 2-year follow-up, when compared to patients who were normal weight at diagnosis $(\mathrm{OR}=3.7 ; 95 \% \mathrm{CI}, 1.2-11.0$ for females and $\mathrm{OR}=$ 4.4; $95 \%$ CI, 1.4 to 13.7 for males). Similar trends were seen at the 5 year follow-up with patients more likely to be overweight/obese if they were overweight/obese at diagnosis $(\mathrm{OR}=5.0 ; 95 \% \mathrm{CI}, 1.2-21.0$ for females and $\mathrm{OR}=2.9 ; 95 \% \mathrm{CI}, 0.66-12.8$ for males).

\subsection{Time Frames for an Increase in Mean BMI Percentile}

Table 4 shows the mean BMI percentiles by gender at diagnosis, end of treatment, and 2-year follow-up. These are further broken down by BMI category at diagnosis. ALL survivors had a significant increase in BMI percentile between diagnosis and end of therapy ( $<<0.05$ for females and males) and between diagnosis and 2-year follow-up ( $<<0.05$ for females and males). The same finding was found in female and male survivors who were underweight and normal weight at diagnosis. When looking at survivors who were overweight/obese at diagnosis, there is a trend toward decreasing weight over time. However, as shown in Figures $\mathbf{1}$ and 2, these patients were still more likely to have higher BMI percentiles at their 2-year follow-up as compared to those who were normal weight or underweight at diagnosis. The data obtained for the ALL survivors who returned for a 5 year visit showed all the same trends, with the addition of females having BMI increased between diagnosis and 5 year follow-up $(p<0.05)$. There was no significant increase in BMI percentile between end of therapy and 2- 
Risk Factors for Obesity and Time Frame of Weight Gain in Non-Irradiated Survivors of Pediatric Acute Lymphoblastic Leukemia

Table 4. Mean BMI Percentile across time of patients with 2 years of follow-up.

\begin{tabular}{|c|c|c|c|c|c|c|c|c|c|}
\hline & & & & & & & \multicolumn{3}{|c|}{ p-values for change across time } \\
\hline & $\begin{array}{l}\text { Dx } \\
\text { (1) }\end{array}$ & $\begin{array}{l}\text { St Err } \\
\text { (1) }\end{array}$ & $\begin{array}{c}\text { End of } T x \\
\text { (2) }\end{array}$ & $\begin{array}{l}\text { St Err } \\
\text { (2) }\end{array}$ & 2-year follow up (3) & $\begin{array}{l}\text { St Err } \\
\text { (3) }\end{array}$ & $\begin{array}{l}\text { (1) to } \\
\text { (2) }\end{array}$ & $\begin{array}{l}\text { (2) to } \\
\text { (3) }\end{array}$ & $\begin{array}{l}\text { (1) to } \\
\text { (3) }\end{array}$ \\
\hline Females & 62.8 & 3.9 & 79.6 & 3.0 & 74.3 & 3.0 & $<0.05$ & 0.06 & $<0.05$ \\
\hline \multicolumn{10}{|l|}{$\begin{array}{l}\text { BMI wt category } \\
\text { at diagnosis }\end{array}$} \\
\hline Underweight & 2.6 & 1.3 & 85.5 & 5.8 & 69.9 & 12.2 & $<0.05$ & 0.20 & $<0.05$ \\
\hline Normal & 48.4 & 3.6 & 76.3 & 3.9 & 69.0 & 4.1 & $<0.05$ & $<0.05$ & $<0.05$ \\
\hline Overweight/Obese & 95.1 & 0.9 & 84.4 & 5.1 & 83.9 & 4.4 & $<0.05$ & 0.92 & $<0.05$ \\
\hline Males & 63.2 & 4.1 & 76.9 & 3.0 & 79.4 & 2.8 & $<0.05$ & 0.25 & $<0.05$ \\
\hline \multicolumn{10}{|l|}{$\begin{array}{l}\text { BMI wt category } \\
\text { at diagnosis }\end{array}$} \\
\hline Underweight & 1.3 & 0.7 & 58.0 & 15.8 & 71.6 & 12.8 & $<0.05$ & 0.45 & $<0.05$ \\
\hline Normal & 51.8 & 4.3 & 70.3 & 4.0 & 74.3 & 4.0 & $<0.05$ & 0.10 & $<0.05$ \\
\hline Overweight/Obese & 94.8 & 0.9 & 91.3 & 2.0 & 88.8 & 2.8 & 0.12 & 0.31 & 0.06 \\
\hline
\end{tabular}

Abbreviations: BMI, body mass index; Wt, weight; Dx, Diagnosis; St Err, Standard Error; Tx, treatment.

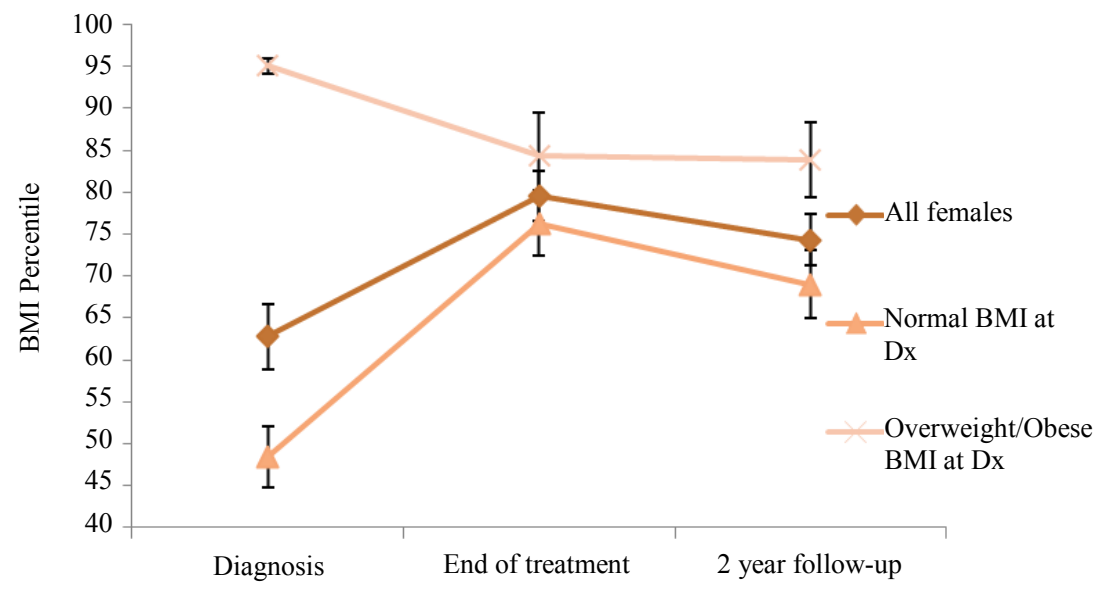

Figure 1. Mean BMI percentiles \pm standard error of mean of female ALL survivors. The points marked represent the mean value for 3 different time points: at diagnosis, end of treatment, and at the 2-year follow-up appointment post treatment.

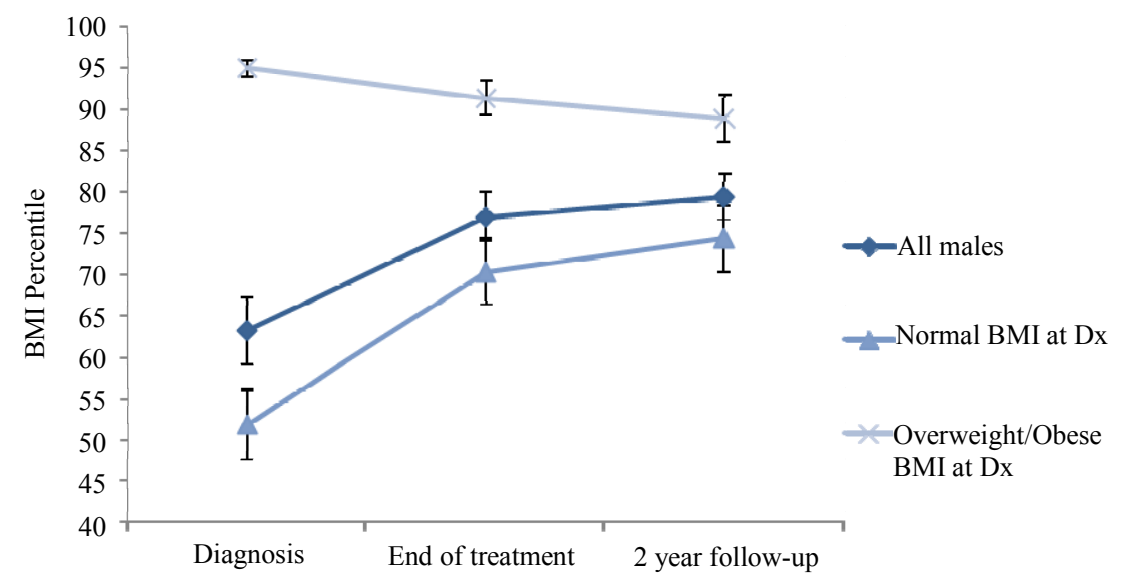

Figure 2. Mean BMI percentiles \pm standard error of mean of male ALL survivors. The points marked represent the mean value for 3 different time points: at diagnosis, end of treatment, and at the 2-year follow-up appointment post treatment. 
or 5- year follow-up visits (data not shown).

\section{Discussion}

The prevalence of overweight and obesity was higher in our population of ALL cancer survivors at both 2 years after treatment $(52.3 \%)$ and 5 years after treatment (49.5\%) from that of the general population (31.7\%) [17]. Factors that helped predict overweight/obesity in long term survivors involved the diagnosis of ALL, white and Hispanic ethnicity, and having a BMI $\geq 85$ th percentile at diagnosis. Our study, which excluded irradiated patients, supports the hypothesis that several factors besides cranial radiation are involved in weight gain in ALL survivors.

Numerous studies have shown an increase in weight in survivors of ALL, but have disagreed on which factors are responsible. The etiology of weight gain is likely multifactorial, with an interaction between genetics and the environment. Genetic studies have found obese female survivors of ALL to be more likely homozygous for a polymorphism of the leptin receptor that is associated with obesity [18]. Ethnicity also comes into play, and similar to our study, others have found Hispanics to be at increased risk of obesity [6]. While our study did not find the age of diagnosis to be a risk factor in developing obesity, many other studies have. Some show children younger than 13 years at diagnosis have increased BMI at follow-up, due to decreased height as opposed to increased weight [19], while others document younger ages (less than 6 years [3] or less than 4 years [20] of age). One theory that attempts to explain this trend is that of premature adiposity rebound. Adiposity rebound occurs in all children at around ages 5 to 7 , and is the period when BMI and other indices of adiposity increase after reaching its nadir. It is thought that adiposity rebound occurs prematurely in ALL patients if treated at a young age, preventing them from reaching their true nadir, thus leading to an increased risk of obesity [21].

While we had collected data on chemotherapy and steroids received by each of the patients, for this study, we did not compare the impact of different chemotherapy agents on weight. We did note, however, an increase in weight gain during the ALL treatment period. Like our results, many studies have also seen weight increase during therapy that persists into follow-up [22], but no difference in BMI between the end of therapy and most recent follow-up [23]. This seems to imply that the treatment for ALL, including chemotherapy and steroids, is likely a major factor in the etiology of weight gain. Chemotherapy is thought to have an effect on impairing growth hormone secretion, thus leading to the adverse metabolic consequences (increase percentage total body fat and unfavorably lipid profile) during treatment [24]. In one study, growth hormone deficiency was seen in $20 \%$ of ALL adult survivors treated without cranial irradiation [25]. Despite these findings and theories, oeffinger et al. demonstrated no chemotherapy agent, either individually or in combination, to be significantly associated with overweight or obesity in ALL survivors during or after treatment [8]. Steroids are known to have an effect on weight gain, but the cumulative dose that puts patients at a significant risk for increasing BMI is still unknown. It has been shown that not all steroids have the same effect on weight gain, with dexamethasone primarily having a short term effect and prednisone having a prolonged effect [26].

Patients' lifestyle during and after treatment is an important variable that was not adjusted for in this study. As weight gain is a balance between energy expenditure and intake, it is imperative to monitor both closely. Most studies have shown no effect of ALL on resting energy expenditure [27]. Weight gain could then be due to decreased energy expenditure, such as increased number of television hours [28], or increased intake [29]. ALL treatment can be associated with motor impairment, deconditioning, and chemotherapy-related effects such as neuropathy, which can all lead to decreased exercise. Psychosocial factors, such as parent behaviors of monitoring, pressure and restriction are highly correlated with increased BMI in children [29].

\section{Conclusions}

These findings support the necessity of preventative efforts, early recognition and intervention in the management of overweight/obesity in children with ALL. While our focus during treatment continues to be the eradication of leukemia, it is imperative that we address this problem concomitantly, to prevent long term morbidities. Special attention should be paid to both Hispanic and white children, and those who are obese or overweight at diagnosis. Although our data also showed underweight children becoming overweight/obese at their 2-year follow-up appointment, given our low sample size for underweight children, these results are not statistically significant (see Table 3). The optimal time for intervention seems to be during treatment, as those that gain weight during therapy tend to keep gaining weight afterwards. The actual intervention methods need to be better defined. A multifactorial approach is likely needed. Nutritionist involvement, during and after the treatment to help calculate caloric needs and develop an individualized nutritional plan for the child, is important. Input from an exercise specialist to discuss patient habits and offer exercise options based on the child's capability at the time 
will also be helpful. Additionally, a psychologist that can evaluate and discuss the patient's self esteem, family dynamics, and any non-physical limitations to an active and healthy lifestyle should be integrated in the overall plan of care.

There are limitations to this study. As this is a retrospective chart review, measurement of height and weight was done at each clinic visit and was not standardized. Though the clinic has only one scale so the same scale was likely utilized in measuring the weight, both height and weight were measured by different operators at each visit and could contribute to different values. Although similar trends are seen at the 2-year and 5 year follow-up appointments, since many patients were lost to follow-up by the 5 year point, many of those results are not significant. Our patient population is skewed to have a significantly higher number of Hispanic patients than all other ethnicities, and we did not have a good sample size of Asian and Black ethnicities. Although we saw Hispanics and whites to both have increased odds of being overweight or obese as compared to the general population, our study cannot make any conclusions on other ethnicities. As mentioned earlier, with our sample size, we were unable to look into the effects of varying doses of different steroids on BMI. In the future, there needs to be a study that better delineates how specific dosages of dexamethasone or prednisone affect BMI and help define the minimum dose of steroids that lead to a significant increase in BMI. A study with sibling matched controls to better decipher the impact of ALL therapy from the socioeconomic and lifestyle factors is also necessary

\section{REFERENCES}

[1] C. Ogden and M. Carroll, "Prevalence of Obesity among Children and Adolescents: United States, Trends 19631965 through 2007-2008," 2010.

http://www.cdc.gov/nchs/data/hestat/obesity_child_07_08 /obesity_child_07_08.htm.

[2] V. K. Dalton, M. Rue, L. B. Silverman, R. D. Gelber, B. L. Asselin, R. D. Barr, L. A. Clavell, C. A. Hurwitz, A. Moghrabi, Y. Samson, M. Schorin, N. J. Tarbell, S. E. Sallan and L. E. Cohen, "Height and Weight in Children Treated for Acute Lymphoblastic Leukemia: Relationship to CNS Treatment," Journal of Clinical Oncology, Vol. 21, No. 15, 2003, pp. 2953-2960. doi: $10.1200 / \mathrm{JCO} .2003 .03 .068$

[3] B. I. Razzouk, S. R. Rose, S. Hongeng, D. Wallace, M. P. Smeltzer, M. Zacher, C. H. Pui and M. M. Hudson, "Obesity in Survivors of Childhood Acute Lymphoblastic Leukemia and Lymphoma," Journal of Clinical Oncology, Vol. 25, No. 10, 2007, pp. 1183-1189. doi:10.1200/JCO.2006.07.8709

[4] N. Howlader, A. M. Noone, M. Krapcho, N. Neyman, R. Aminou, W. Waldron, S. F. Altekruse, C. L. Kosary, J.
Ruhl, Z. Tatalovich, H. Cho, A. Mariotto, M. P. Eisner, D. R. Lewis, H. S. Chen, E, J. Feuer and K. A. Cronin, "SEER Cancer Statistics Review, 1975-2009 (Vintage 2009 Populations)," 2012.

http://seer.cancer.gov/csr/1975_2009_pops09/.

[5] S. J. Veringa, E. van Dulmen-den Broeder, G. J Kasparas and M. A. Veening, "Blood Pressure and Body Composition in Long-Term Survivors of Childhood Acute Lymphoblastic Leukemia," Pediatric Blood Cancer, Vol. 25, No. 2, 2012, pp. 278-282. doi:10.1002/pbc.23251

[6] L. Iughetti, P. Bruzzi, B. Predieri and P. Paolucci, "Obesity in Patients with Acute Lymphoblastic Leukemia in Childhood," Italian Journal of Pediatrics, Vol. 38, No. 4, 2012.

[7] H. L. Mueller, "Consequences of Craniopharyngioma Surgery in Children," The Journal of Clinical Endocrinology and Metabolism, Vol. 96, No. 7, 2011, pp. 19811991. doi:10.1210/jc.2011-0174

[8] K. C. Oeffinger, A. C Mertens, C. A. Sklar, Y. Yasui, T. Fears, M. Stovall, T. A. Vik, P. D. Inskip and L. L. Robison, "Obesity in Adult Survivors of Childhood Acute Lymphoblastic Leukemia: A Report from the Childhood Cancer Survivor Study," Journal of Clinical Oncology, Vol. 21, No. 7, 2003, pp. 1359-1365. doi:10.1200/JCO.2003.06.131

[9] L. R. Meacham, J. G. Gurney, A. C. Mertens, K. K. Ness, C. A. Sklar, L. L. Robison and K. C. Oeffinger, "Body Mass Index in Long-Term Adult Survivors of Childhood Cancer: A Report of the Childhood Cancer Survivor Study," Cancer, Vol. 103, No. 8, 2005, pp. 1730-1739. doi:10.1002/cncr.20960

[10] C. A. Sklar, A. C. Mertens, A. Walter, D. Mitchell, M. E. Nesbit, M. O'Leary, R. Hutchinson, A. T. Meadows and L. L. Robison, "Changes in Body Mass Index and Prevalence of Overweight in Survivors of Childhood Acute Lymphoblastic Leukemia: Role of Cranial Irradiation," Medical and Pediatric Oncology, Vol. 35, No. 2, 2000, pp. 91-95.

doi:10.1002/1096-911X(200008)35:2<91::AID-MPO1>3. $0 . \mathrm{CO} ; 2-\mathrm{G}$

[11] C. A. Brouwer, J. A. Gietema, J. M. Vonk, W. J. Tissing, H. M. Boezen, N. Zwart and A. Postma, "Body Mass Index and Annual Increase of Childhood Cancer Survivors; Relationship to Treatment," Support Care Cancer, Vol. 20, No. 2, 2012, pp. 311-318. doi:10.1007/s00520-010-1080-x

[12] F. Craig, A. D. Leiper, R. Stanhope, C. Brain, S. T. Meller and S. S. Nussey, "Sexually Dimorphic and Radiation Dose Dependent Effect of Cranial Irradiation on Body Mass Index," Archives of Disease in Childhood, Vol. 81, No. 6, 1999, pp. 500-504. doi:10.1136/adc.81.6.500

[13] I. Odame, J. J. Reilly, B. E. S. Gibson and M. D. C. Donaldson, "Patterns of Obesity in Boys and Girls After Treatment of Acute Lymphoblastic Leukemia," Archives of Disease in Childhood, Vol. 71, No. 2, 1994, pp. 147149. doi:10.1136/adc.71.2.147

[14] R. J. Kuczmarski, C. L. Ogden, S. S. Guo, L. M. Grum- 
mer-Strawn, K. M. Flegal, Z. Mei, R. Wei, L. R. Curtin, A. F. Roche and C. L. Johnson, "CDC growth charts for the United States: Methods and development," National Center for Health Statistics Vital Health Stat, Vol. 11, No. 246, 2002, pp. 31-32.

[15] K. M. Flegal, C. J. Tabak and C. L. Ogden, "Overweight in Children: Definitions and Interpretation," Health Education Research, Vol. 21, No. 6, 2006, pp. 755-760. doi: $10.1093 /$ her $/$ cyl128

[16] L. D. Hammer, H. C. Kraemer, D. M. Wilson, P. L. Ritter and S. M. Dornbusch, "Standardized Percentile Curves of Body-Mass Index for Children and Adolescents," American Journal of Diseases of Children, Vol. 145, No. 3, 1991, pp. 259-263.

[17] C. L. Ogden, M. D. Carroll MD, L. R. Curtin, M. M. Lamb and K. M. Flegal, "Prevalence of High Body Mass Index in US Children and Adolescents, 2007-2008," The Journal of the American Medical Association, Vol. 303, No. 3, 2010, pp. 242-249. doi:10.1001/jama.2009.2012

[18] J. A. Ross, K. C. Oeffinger, S. M. Davies, A. C. Mertens, E. K. Langer, W. R. Kiffmeyer, C. A. Sklar, M. Stovall, Y. Yasui and L. L. Robison, "Genetic Variation in the Leptin Receptor Gene and Obesity in Survivors of Childhood Acute Lymphoblastic Leukemia: A Report from the Childhood Cancer Survivor Study," Journal of Clinical Oncology, Vol. 22, No. 17, 2004, pp. 3558-3562. doi:10.1200/JCO.2004.11.152

[19] V. K. Dalto, M. Rue, L. B. Silverman, R. D. Gelber, B. L. Asselin, R. D. Barr, L. A. Clavell, C. A. Hurwitz, A. Maghrabi, Y. Samson, M. Schorin, N. J. Tarbell, S. E. Sallan and L. E. Cohen, "Height and Weight in Children Treated for Acute Lymphoblastic Leukemia: Relationship to CNS Treatment," Journal of Clinical Oncology, Vol. 21, No. 15, 2003, pp. 2953-2960. doi:10.1200/JCO.2003.03.068

[20] J. G. Gurney, K. K. Ness, M. Stoval, S. Wolden, J. A. Punyko, J. P. Neglia, A. C. Mertens, R. J. Packer, L. L. Robison and C. A. Sklar, "Final Height and Body Mass Index Among Adult Survivors of Childhood Brain Cancer: Childhood Cancer Survivor Study," The Journal of Clinical Endocrinology and Metabolism, Vol. 88, No. 10, 2003, pp. 4731-4739. doi:10.1210/jc.2003-030784

[21] J. J. Reilly, A. Kelly, P. Ness, A. R. Dorosty, W. H. Wallace, B. E. Gibson and P. M. Emmett and ALSPAC Study Team, "Premature Adiposity Rebound in Children Treated for Acute Lymphoblastic Leukemia," The Journal of Clinical Endocrinology and Metabolism, Vol. 86, No. 6,
2001, pp. 2775-2778. doi:10.1210/jc.86.6.2775

[22] R. A. Breene, R. M. Williams, J. Hartle, M. Gattens, C. L. Acerini and M. J. Murray, "Auxological Changes in UK Survivors of Childhood Acute Lymphoblastic Leukaemia Treated Without Cranial Irradiation," British Journal of Cancer, Vol. 104, No. 5, 2011, pp. 746-749. doi:10.1038/bjc.2011.16

[23] P. C. Nathan, V. Jovcevska, K. K. Ness, N. MammoneD'Agostino, P. Staneland, S. L. Urbach, M. Barron, M. Barrera and M. L. Greenberg, "The Prevalence of Overweight and Obesity in Pediatric Survivors of Cancer," The Journal of Pediatrics, Vol. 149, No. 4, 2006, pp. 518-525. doi:10.1016/j.jpeds.2006.06.039

[24] M. Jarfelt, B. Lannering, I. Bosaeus, G. Johannsson and R. Bjarnason, "Body Composition in Young Adult Survivors of Childhood Acute Lymphoblastic Leukaemia," European Journal of Endocrinology, Vol. 153, No. 1, 2005, pp. 81-89. doi:10.1530/eje.1.01931

[25] J. G. Gurney, K. K. Ness, S. D. Sibley, M. O'eary, D. R. Dengel, J. M. Lee, N. M. Youngren, S. P. Glasser and K. S. Baker, "Metabolic Syndrome and Growth Hormone Deficiency in Adult Survivors of Childhood Acute Lymphoblastic Leukemia," Cancer, Vol. 107, No. 6, 2006, pp. 1303-1312. doi: $10.1002 / \mathrm{cncr} .22120$

[26] J. E. W. M. Van Dongen-Melman, A. C. S. HokkenKoelega, K. Hahlen, A. De Groot and C. G. Tronmp, "Obesity after Successful Treatment of Acute Lymphoastic Leukemia in Childhood," Pediatric Research, Vol. 38 , No. 1, 1995, pp. 86-90. doi:10.1203/00006450-199507000-00015

[27] C. S. Tam and E. Ravussin, "Energy Balance: An Overview with Emphasis on Children," Pediatric Blood \& Cancer, Vol. 58, No. 1, 2012, pp. 154-158. doi: $10.1002 /$ pbc. 23375

[28] T. L. Miller, S. R. Lipsitz, G. Lopez-Mitnik, A. S. Hinkle, L. S. Constine, M. J. Adams, C. French, C. Proukou, A. Rovitelli and S. E. Lipshultz, "Characteristics and Determinants of Adiposity in Pediatric Cancer Survivors," Cancer Epidemiology, Biomarkers, and Prevention, Vol 19, No. 8, 2010, pp. 2012-2022. doi:10.1158/1055-9965.EPI-10-0163

[29] J. Cohen, C. E. Wakefield, C. A Fleming, R. Gawthorne. L. C. Tapsell and R. J. Cohn, "Dietary Intake after Treatment in Child Cancer Survivors," Pediatric Blood and Cancer, Vol. 58, No. 5, 2012, pp. 752-757. doi: $10.1002 / \mathrm{pbc} .23280$ 